\title{
Characterization of Phytophthora infestans Populations in Western Washington
}

\author{
A. E. Dorrance, Department of Plant Pathology, The Ohio State University, Wooster 44691; D. A. Inglis and M. L. \\ Derie, Washington State University, Mount Vernon-Research and Extension Unit, 16650 State Route 536, Mount \\ Vernon 98273-9761; C. R. Brown, United States Department of Agriculture, Agricultural Research Service, Irri- \\ gated Agricultural Research and Extension Center, Prosser, WA 99350; S. B. Goodwin, USDA-ARS, Department \\ of Botany and Plant Pathology, Purdue University, West Lafayette, IN 47907; W. E. Fry, Plant Pathology \\ Department, Cornell University, Ithaca, NY 14853; and K. L. Deahl, USDA-ARS, Vegetable Laboratory, Beltsville, \\ MD 20705
}

\begin{abstract}
Dorrance, A. E., Inglis, D. A., Derie, M. L., Brown, C. R., Goodwin, S. B., Fry, W. E., and Deahl, K. L. 1999. Characterization of Phytophthora infestans populations in western Washington. Plant Dis. 83:423-428.

The first detection in the United States of isolates of Phytophthora infestans having metalaxyl insensitivity and complex pathotypes occurred in western Washington during the early 1990s. To determine the genetic structure of the current population in western Washington, a total of 115 isolates of $P$. infestans were obtained during 1996 from infected tubers or foliage of potato, tomato, nightshade, and bittersweet throughout the region. An additional 45 isolates were collected from a single field. Based on mating type, metalaxyl-insensitivity, and molecular markers (allozymes of glucose-6-phosphate isomerase, peptidase, and RG57 DNA fingerprint), all of the isolates were A1 mating type and had the US-11 multilocus genotype. Analyses of an additional 120 isolates collected during 1997 from potato, tomato, and nightshade were performed. As in 1996, US-11 was the predominant genotype detected on all three hosts. However, three additional A2 mating type genotypes were also detected: US-7, US-8, and US-14. These three genotypes represent the first A2 mating type isolates detected in western Washington. Most of a subset of 60 isolates infected 4 to 7 of the 10 potato differentials tested. This included $90 \%$ of the isolates collected in 1996 (all US-11), plus 72\% of the US-11 and 100\% of the US-8 and US14 isolates collected during 1997. Virulence phenotypes in this region are complex even without the selection pressure of R-genes in the local commercial cultivars. The apparent increase in genetic variation observed in populations of $P$. infestans in western Washington from 1996 to 1997 most likely occurred by migration rather than by sexual recombination.
\end{abstract}

Additional keywords: late blight

Late blight of potato, caused by the fungus Phytophthora infestans (Mont.) de Bary, has been a production constraint in western Washington since 1990, when the first metalaxyl-insensitive isolates of $P$. infestans were detected (5,7). Some of the most complex virulence pathotypes among isolates of $P$. infestans in North America outside Mexico also have been reported from this region $(7,19)$. Moreover, parts of western Washington adjoin British Columbia, Canada, where the A2 mating type was first reported in $1989(2,4,5)$. Evidence that isolates collected in northwestern Washington and British Columbia, Canada, originated by sexual recombination has subsequently been presented (18).

Potatoes are well-adapted to this coastal region west of the Cascade Mountains,

Corresponding author: D. A. Inglis

E-mail: dainglis@ coopext.cahe.wsu.edu

Accepted for publication 30 November 1998.

Publication no. D-1999-0302-01R

(C) 1999 The American Phytopathological Society which is distinguished by a mild marine climate $(83 \mathrm{~cm}$ annual precipitation and $15.2 / 1.7^{\circ} \mathrm{C}$ average annual $\mathrm{max} / \mathrm{min}$ temperature). This climate can also be highly conducive to late blight, which occurs annually (9). Red and white potatoes for fresh market predominate production, although some russet and chipping types are also produced. Despite annual outbreaks of late blight, commercial production in northwestern counties of Washington has increased from 1,520 ha in 1990 (41) to 3,838 ha total production in 1997 (D. Havens, personal communication). In southwestern Washington and the Olympic Peninsula, only a few commercial potato fields exist and typically are grown under organic production systems. As a consequence of a large urban population, tomatoes are widely grown in home gardens and nurseries throughout the entire region and are often in close proximity to commercial production fields. Western Washington contrasts with the semiarid region of the Columbia Basin and eastern Washington, where mainly Russet-type potatoes for processing are produced commercially under irrigation on approximately 57,600 ha (42).
Prior to 1989, the US-1 genotype of $P$. infestans was probably the predominant genotype in this area, as it was throughout the world (13). Goodwin et al. (12) reported a number of genotypes among isolates collected from northwestern Washington and British Columbia during 1990 and 1991, including US-6, US-6.2, US-6.3, US-6.4, US-6.5, CDA-2, and CDA-3, among which only CDA-3 from British Columbia was of the A2 mating type. In 1992, the isolates from western Washington that were analyzed for allozyme and DNA fingerprint were all US-6 (18). Samples collected from blighted foliage from northwestern Washington during 1994 consisted of a previously undescribed genotype, US-11, which is A1 mating type $(10,16,23)$.

Two previous studies have assessed pathotype diversity among US-6 isolates from the northwestern Washington population of $P$. infestans $(7,19)$. Deahl et al. (7) were the first to identify complex races: 4 out of $32(12.5 \%)$ evaluated had six or more virulence factors. Goodwin et al. (19) evaluated 77 isolates of $P$. infestans for their pathogenicity phenotype, including eight isolates from northwestern Washington. Six of the isolates had virulence to seven, one isolate to four, and one isolate had virulence to three potato resistance genes. All of these isolates were pathogenic on tomato without R-genes and on the two tomato differential cultivars tested. In addition, hairy nightshade (Solanum sarachoides Sendtner ex. Mart.) was identified as another host for $P$. infestans in northwestern Washington (6). Isolates from hairy nightshade have also proved to be complex, with six (6) or seven virulence factors (19). The pathotype diversity among US-11 isolates from this region has not yet been assessed.

Several hypotheses have been proposed to predict the consequences of new genotypes of $P$. infestans migrating into commercial potato production regions of the United States and Canada. Goodwin et al. (19) noticed a rapid loss of pathogenicity within the US-6 clonal lineage and proposed that pathogenicity to many resistance genes may be lost within clonal pathogen populations. Vanderplank (40) proposed a similar hypothesis called 
"stabilizing selection against unnecessary virulence genes." Some possible results from the establishment of sexually reproducing populations of $P$. infestans throughout the United States and Canada have been discussed (12), but they never have been tested experimentally. Western Washington represents a unique natural laboratory for evaluating some of these hypotheses because (i) it is the first location in North America in which insensitivity to metalaxyl was detected (7); (ii) highly complex pathotypes of $P$. infestans have been detected since the early 1990s $(7,19)$; (iii) the first detection of probable sexual reproduction in North America outside Mexico was immediately north, in British Columbia during 1992 (18); (iv) the mild climate favors consecutive epidemics and interaction among new or introduced genotypes; (v) previous studies (4-7,12,16, $18,19,23$ ) provide an initial baseline for estimating changes in recent populations; and (vi) assorted susceptible hosts including hairy nightshade, volunteer and commercial potatoes, garden tomatoes, and bittersweet (Solanum dulcamara L.) are juxtaposed in the region.

The purpose of this study was to use neutral genetic markers to characterize the western Washington $P$. infestans population and to establish baseline data of virulence pathotypes.

\section{MATERIALS AND METHODS}

Sources of isolates and culture of $P$. infestans. Plant tissue infected with $P$. infestans was obtained from farm managers, potato producers, WSU-Puyallup Plant Disease Clinic, master gardeners, private consultants, and home gardeners in the Washington counties west of the Cascade Mountains during 1996 and 1997. In addition, foliar lesions (45 samples total) were collected approximately every $10 \mathrm{~m}$ from late blight field plots where Solanum germ plasm was evaluated for resistance during
1996 at WSU-Mount Vernon. Samples were received as infected foliage, tubers, or fruits of potato, tomato, hairy nightshade, and bittersweet. Depending on the quality of the sample, one to eight distinct foliar, tuber, or fruit lesions caused by $P$. infestans were isolated into pure culture using two methods. In the first method, infected tissues from tubers and fruit were rinsed under tap water, surface-sterilized in $0.5 \%$ sodium hypochlorite for $30 \mathrm{~s}$, and rinsed twice in distilled water. Potato tuber pieces were dipped in a benomyl suspension (50 mg 50\% Benlate WP per $100 \mathrm{ml}$ ) (in order to retard Fusarium spp. development) prior to placement onto a selective medium (rye agar amended with $20 \mathrm{mg}$ of rifamycin, $200 \mathrm{mg}$ of vancomycin, $200 \mathrm{mg}$ of ampicillin, $68 \mathrm{mg}$ of PCNB, and $50 \mathrm{mg}$ $50 \%$ Benlate WP per liter) $(29,37,38)$. Plates were incubated for 4 to 5 days at $20^{\circ} \mathrm{C}$, then sporangia were transferred to rye agar. For the second method, foliage and stem tissues were placed in moist chambers for 24 to $48 \mathrm{~h}$; sporangia were then transferred via a 5 to $7 \mathrm{~mm}^{3}$ piece of healthy tuber tissue cut from a surfacedisinfested tuber and placed directly onto rye agar selective medium. Cultures were incubated at 18 to $20^{\circ} \mathrm{C}$ for 4 days; sporangia were collected from the tuber piece and transferred to rye agar amended with sucrose $(1.0 \mathrm{~g} /$ liter $)$ to obtain pure cultures. Several isolations were made per site. However, only one isolate per lesion on a leaf or tuber was cultured. Only one lesion per leaf was sampled, but one to five lesions per sample or location were sampled. Long-term maintenance of isolates was on slants of rye agar plus sucrose at $10^{\circ} \mathrm{C}$ under sterile mineral oil (39).

Characterization of isolates. Isolates were analyzed for mating type, sensitivity to metalaxyl, and genotype at the two allozyme loci, glucose-6-phosphate isomerase (Gpi, E.C. 5.3.1.9) and peptidase (Pep, E.C. 3.4.3.1). Isolates were paired

Table 1. Genotypes of Phytophthora infestans detected in western Washington during 1996 and 1997

\begin{tabular}{lccccc}
\hline Host $^{\mathbf{a}}$ & Genotype $^{\mathbf{b}}$ & Mating type & $\boldsymbol{G p i}^{\mathbf{c}}$ & $\boldsymbol{P e p}^{\mathbf{d}}$ & No. of isolates \\
\hline 1996 & & & & & \\
Potato & US-11 & A1 & $100 / 100 / 111$ & $100 / 100$ & 90 \\
Potato & US-11 & A1 & $100 / 100 / 111$ & $100 / 100$ & 45 \\
Tomato & US-11 & A1 & $100 / 100 / 111$ & $100 / 100$ & 19 \\
Nightshade & US-11 & A1 & $100 / 100 / 111$ & $100 / 100$ & 5 \\
Bittersweet & US-11 & A1 & $100 / 100 / 111$ & $100 / 100$ & 1 \\
Total & & & & & 160 \\
1997 & & & & & \\
Potato & US-11 & A1 & $100 / 100 / 111$ & $100 / 100$ & 51 \\
Potato & US-8 & A2 & $100 / 111 / 122$ & $100 / 100$ & 25 \\
Potato & US-14 & A2 & $100 / 122$ & $100 / 100$ & 6 \\
Tomato & US-11 & A1 & $100 / 100 / 111$ & $100 / 100$ & 30 \\
Tomato & US-7 & A2 & $100 / 111$ & $100 / 100$ & 6 \\
Nightshade & US-11 & A1 & $100 / 100 / 111$ & $100 / 100$ & 2 \\
Total & & & & & 120 \\
\hline
\end{tabular}

${ }^{\text {a }}$ Nightshade $=$ Solanum sarachoides $;$ bittersweet $=$ S. dulcamara .

${ }^{\mathrm{b}}$ US genotype designations sensu Goodwin et al. $(16,18)$.

c Glucose-6-phosphate isomerase.

d Peptidase.

${ }^{\mathrm{e}}$ P. infestans isolates collected from one field at WSU-Mount Vernon REU. with known A1 and A2 tester strains on rye agar or rye agar with sucrose. Isolates that produced oospores when paired with the A1 tester strain were designated A2, and isolates that produced oospores with the A2 tester strain were designated A1 when scored after 2 to 3 weeks.

Radial growth on metalaxyl-amended rye agar, as described by others $(7,20$, 29,30), was used to estimate metalaxyl sensitivity. A 5-mm colonized plug from a 7- to 14-day-old colony was placed on rye agar amended with 0,5 , or $100 \mu \mathrm{g}$ of metalaxyl per ml. Two stock solutions of technical-grade metalaxyl were prepared as 5 and $100 \mathrm{mg} / \mathrm{ml}$ in pure dimethylsulfoxide (DMSO). Control plates were amended with the same concentrations of DMSO as metalaxyl-amended plates, and there were two replicates of each metalaxyl concentration for each isolate. Plates were scored after 7 to 10 days by measuring the diameter of the colony and subtracting $5 \mathrm{~mm}$ to correct for the plug. The mean colony diameters at 5 and $100 \mu \mathrm{g}$ of metalaxyl per $\mathrm{ml}$ were divided by the mean colony diameter on the control plates. Isolates that grew more than $40 \%$ of the control on metalaxyl medium of $5 \mu \mathrm{g} / \mathrm{ml}$ were considered to be resistant (20).

Mycelia from 7- to 14-day-old rye agar plus sucrose plates were used to analyze the two allozyme loci, Gpi and Pep, using cellulose-acetate electrophoresis as described by Goodwin et al. (15). Allozyme alleles were designated by the numbers representing their percent mobility relative to previously established standards $(10,12,17)$.

A subset of 45 isolates collected during 1996 was further analyzed with DNA probe RG57 as described by Goodwin et al. (14). Mycelia were grown on rye agar with sucrose for 14 to 21 days at $20^{\circ} \mathrm{C}$. Mycelia were collected from 8 to 10 cultures and ground in liquid nitrogen, vortexed with $4 \mathrm{ml}$ of prewarmed $\left(65^{\circ} \mathrm{C}\right)$ extraction buffer $(50 \mathrm{mM}$ Tris, $\mathrm{pH} 8.0 ; 150$ mM EDTA; $1 \%$ sarkosyl) for 30 to $60 \mathrm{~s}$, and incubated for $20 \mathrm{~min}$ at $65^{\circ} \mathrm{C}$. Next, 4 $\mathrm{ml}$ of cold $5 \mathrm{M} \mathrm{NH}_{4} \mathrm{OAC}$ was added to each tube, then mixed by inversion, placed on ice for $20 \mathrm{~min}$, and centrifuged for 20 $\min$ at $8,240 \times g$. The supernatant was transferred to a glass tube with $5 \mathrm{ml}$ of cold isopropanol and centrifuged for 15 $\min$ at $10,000 \times g$. The supernatant was decanted and the pellets were dried briefly, then resuspended in $0.5 \mathrm{ml}$ of TE plus RNase $(0.1 \mathrm{mg} / \mathrm{ml})$. This was incubated at $37^{\circ} \mathrm{C}$ for $20 \mathrm{~min}$, then extracted twice with 25:24:1 phenol:chloroform:isoamyl alcohol. The DNA was precipitated with onetenth volume of $3 \mathrm{M} \mathrm{NaOAC}$ and one volume of isopropanol. The tubes were centrifuged for 2 min to collect the DNA; then the pellets were dried briefly, washed in cold $70 \%$ ethanol, and resuspended in 100 to $300 \mu \mathrm{l}$ of TE. For each isolate, approximately $2 \mu \mathrm{g}$ of DNA was digested 
with the restriction enzyme EcoRI according to the manufacturer's directions. Gel electrophoresis in $0.8 \%$ agarose gels, alkaline blotting to Hybond $\mathrm{N}+$ nylon membrane, hybridization with ${ }^{32} \mathrm{P}$ random primed RG57 probe, and autoradiography were all according to the manufacturer's instructions (Amersham Life Science, Arlington Heights, IL) and standard protocols (28).

A subset of 60 isolates collected in 1996 and 1997 was analyzed for virulence phenotype on detached leaflets in inverted water agar $(1.5 \%)$ plates as described by Tooley et al. (38). Ten single R-gene differential potato cultivars were obtained from the Potato Introduction Station, Sturgeon Bay, WI: PI 423651 (R1), PI 423652 (R2), PI 423653 (R3), PI 203900 (R4), PI 303146 (R5), PI 587059 (R6), PI 303148 (R7), PI 303149 (R8), LB 1 (R9), and PI 423656 (R10). Two detached leaflets of each differential and a susceptible (R0) cultivar Red LaSoda, Russet Norkotah, or Shepody were placed abaxial side up, two replicates per isolate, for a total of four leaflets. A 50- $\mu$ d droplet containing a suspension of sporangia (1.0 to $2.5 \times 10^{4}$ sporangia per $\mathrm{ml}$ ) was placed on each leaf. Plates were incubated at $18^{\circ} \mathrm{C}$ with a $12-\mathrm{h}$ light:dark cycle. After 7 days, leaflets were scored for the presence or absence of a sporulating lesion. Every isolate was assayed at least twice, with the most consistent reactions reported here.

\section{RESULTS}

1996 collection. A total of 115 isolates of $P$. infestans from single lesions on infected tubers and/or foliage from four different hosts in 40 separate fields and gardens throughout western Washington were collected in 1996. An additional 45 isolates were collected from Solanum late blight resistance evaluation plots at WSU-Mount Vernon. All 160 isolates collected were the US-11 genotype (Table 1), which is A1 mating type, Gpi 100/100/111, Pep $100 / 100$, and resistant to metalaxyl. Isolates were regarded as highly resistant to metalaxyl by mycelial growth of more than $40 \%$ of the control on agar plates amended with $5 \mu \mathrm{g}$ of metalaxyl per ml (Fig. 1). DNA fingerprint analyses of a subset of 45 isolates from 23 locations revealed a clonal population, because all isolates had the same DNA fingerprint (Fig. 2). One isolate from the intensively sampled research plots was missing fingerprint band number 20 .

Virulence phenotypes (Table 2) were quite variable for isolates collected in 1996 , in contrast to the uniformity of the multi-locus genotype determined with neutral genetic markers (Table 1). Previously, US-6 from northwestern Washington had very complex pathotypes present in the population as measured on nine potato differentials (19). In this study, the majority of isolates $(85.7 \%)$ infected four to six potato differentials. Only one isolate in- fected seven differentials. However, the seventh differential was R10, which produced a very slow-growing lesion.

1997 collection. A total of 120 isolates of $P$. infestans were collected from single lesions on infected tubers and/or foliage on three hosts from 45 locations in 1997. Four genotypes of $P$. infestans were detected: US-7, US-8, US-11, and US-14 (Table 1). Genotypes US-7, US-8, and US-14 are the A2 mating type (Table 1). All except two US-8 isolates were highly resistant to metalaxyl (Fig. 1) and represented complex pathotypes (Table 2). The US-8 genotype had an average of 9.0 virulence factors compared with 4.8 for US-11 and 7.0 for US-14.

Differentials R2, R4, and R10 have been reported to have an incomplete hypersensitive response with slowly expanding lesions (3). The differentials were transplanted into the WSU-Mount Vernon research field plots in 1997; the R2 differen- tial did not survive, and all but R8 and R9 had large sporulating lesions and eventually died by the end of the epidemic. These results indicate that a population of $P$. infestans with a highly complex virulence phenotype occurred in the region again in 1997.

\section{DISCUSSION}

During the 1990 through 1997 potato production seasons, populations of $P$. infestans in western Washington have been composed primarily of one or two genotypes with no evidence of sexual recombination. During or shortly before 1990, the US-1 genotype was displaced by US-6 (18), which was subsequently displaced by US-11 during 1994 (16,23). In this study, only the US-11 genotype was identified in 1996; whereas US-7, US-8, US-11, and US-14 were detected in 1997.

We, as well as others, have been able to document these population changes in this

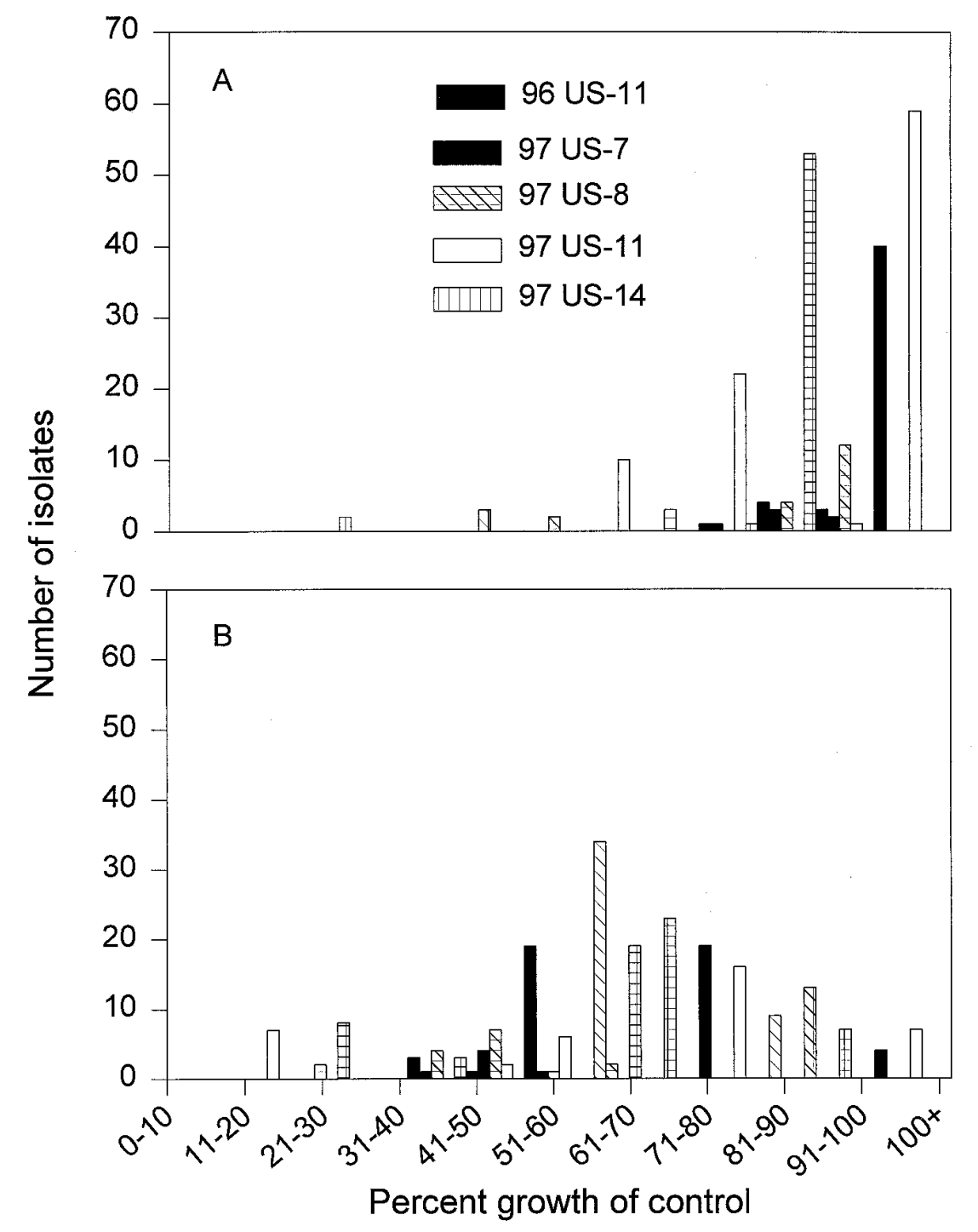

Fig. 1. Relative growth of 115 and 120 isolates of Phytophthora infestans collected from western Washington in 1996 and 1997, respectively. Metalaxyl at (A) $5 \mu \mathrm{g} / \mathrm{ml}$ and (B) $100 \mu \mathrm{g} / \mathrm{ml}$. Radial growth on agar medium containing metalaxyl was expressed as a percentage of growth on agar medium containing $0 \mu \mathrm{g}$ of metalaxyl per $\mathrm{ml}$. 
relatively small potato production region beginning in 1990 using mating type, the allozyme loci Gpi and Pep (18), and metalaxyl insensitivity (7). DNA fingerprint analyses confirmed that the $P$. infestans isolates collected during 1996 (US11) were from a clonal population. The findings in 1997 indicate the $P$. infestans population was composed primarily of two genotypes, US-8 and US-11. The US-8 genotype has been predominant in many of the U.S. potato production regions since the mid-1990s $(11,16,23)$ and is reported to have host specialization for potato (27), although it has been isolated occasionally from hairy nightshade. We similarly collected US-8 on potato but not on tomato. The US-11 genotype in this study has been reported from a few regions (16) but was first described in western Washington during 1994 (10,16,23). This genotype has a very wide host range, including tomato, hairy nightshade, potato (6), and bittersweet. Both the US- 8 and US-11 genotypes of $P$. infestans have complex pathotypes (Table 2; 19). The US-14 genotype also was detected during this study in 1997 from one field in western Washington but has been reported previously in New York (16) and eastern Washington (30). The US7 genotype was recovered during 1997 from home garden tomatoes in several areas of western Washington in which transplants were purchased from garden centers that import tomato seedlings from outside of the production region. The US14 genotype also had complex pathotypes (Table 2). It has been reported previously that US-7 has host specialization on tomato (27).

This is the first documented report of the A2 mating type and the Gpi 122 allele in
12

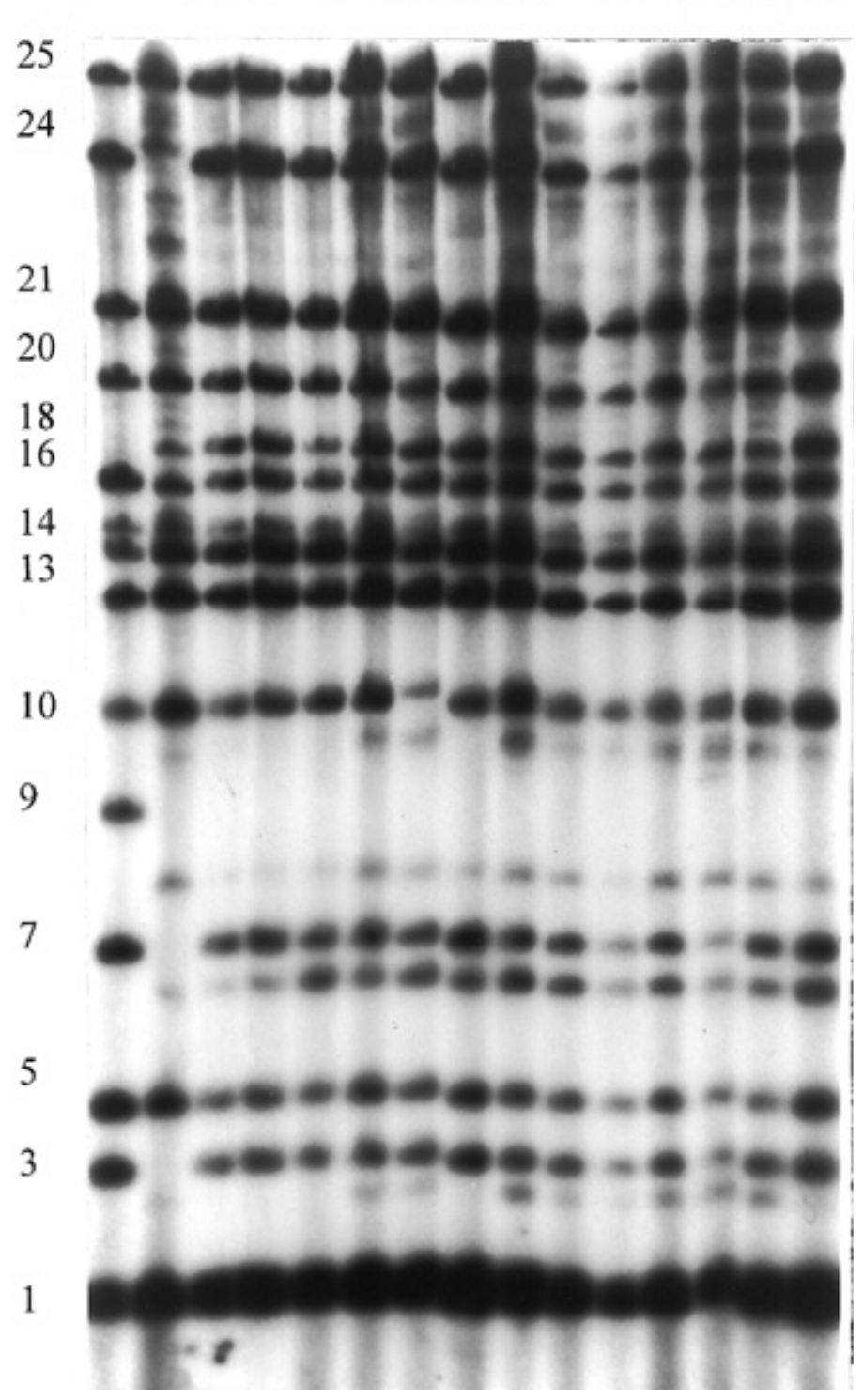

Fig. 2. DNA fingerprint patterns (probe RG57) for Phytophthora infestans standard isolates US-1 (lane 1), US-8 (lane 2), and representative P. infestans US-11 isolates (lanes 3 to 15) collected from throughout western Washington in 1996. Band numbers are indicated on the left.

western Washington and is in contrast to other U.S. and Canadian potato production areas, including eastern Washington, where the A2 mating type has predominated for several years $(2,11,16,18,30,32,33)$. Andrivon and de Vallavieille-Pope (1) stated that the different behavior of geographically distinct populations of the same fungus suggests that local factors are of the utmost importance in the determination of race diversity and complexity patterns. They further suggested that experience with one population of a pathogen is not sufficient to enable a reliable prediction of the structure and evolution of other populations of the same organism, even those that are geographically close. In British Columbia, both metalaxyl-sensitive and metalaxyl-insensitive strains of the A2 mating type were reported in 1992, 1993, and $1994(2,18,20)$, but in 1995 , the majority were A1 and metalaxyl-insensitive (2).

If there were earlier migrations of the A2 mating type from British Columbia into western Washington, they may not have been detected for two possible reasons. First, very few samples were collected in 1993, 1994, and 1995 from western Washington. In addition, 25 and $6 \%$ of the A2 isolates collected in British Columbia during 1993 and 1994, respectively, were metalaxyl-sensitive (2). Since potato producers in western Washington use metalaxyl in their fungicide spray program at the time of tuberization to manage storage rot diseases caused by Pythium spp. and pink rot (Phytophthora erythroseptica (Pethybridge)), they may inadvertently have been selecting for metalaxyl-insensitive strains which were predominantly A1 mating type.

The virulence pathotypes of $P$. infestans collected in this region in 1996 and 1997 were as complex as those reported previously $(6,7,19)$. All differentials except R8 and R9 planted in Mount Vernon field plots in 1997 had large sporulating lesions caused by $P$. infestans and died before the end of the growing season (D. A. Inglis and A. E. Dorrance, unpublished data). The US- 8 and US-14 genotypes on average contained more virulence factors than the "older" US-11 genotypes. These results indicate that the new migrants, US- 8 and US-14, may have originated from a sexually reproducing population $(37,38)$. A sexual population would be more likely to maintain virulence combinations than a population that is reproducing asexually if the observed mutation rate from virulence to avirulence is higher than from avirulence to virulence (19). While the number and types of potato cultivars produced in this region are quite diverse, few if any of these cultivars contain specific resistance genes to $P$. infestans; hence, selection of particular races by $\mathrm{R}$-gene resistance is highly unlikely. In contrast, reports from Poland indicate that isolates prior to mi- 
grations had complex pathotypes, possibly because of the extensive utilization of resistance genes used in commercial cultivars (36).

Both Poland and the Netherlands have reported $P$. infestans populations that are reproducing sexually based on diverse RG57 fingerprints and detection of recombinant allozyme genotypes $(8,35)$. In western Washington, a sexually reproducing population might be detected in the future by the appearance of isolates with homozygous Gpi genotypes (e.g., 100/100, $111 / 111$ ) or by changes in combination of mating type with Gpi allozyme pattern that would result from crosses between US-11 (A1, Gpi 100/100/111) and US-8 (A2, Gpi 100/111/122). Genotypes US-11 (A1) and US-8 (A2) have an extra copy of at least one chromosome, as indicated by the unbalanced Gpi banding pattern (18). However, this should not inhibit formation and germination of oospores as a result of mating between these two genotypes (34; H. Judelson, personal communication). Previous crosses with US- 8 as one parent yield normal numbers of progeny (16). If recombinant genotypes of $P$. infestans are found, this would indicate that oospores could have formed in plants, in fields, or in tubers in storage.

Previous migrations of new $P$. infestans genotypes into U.S. potato and tomato production regions have resulted in one clone predominating $(11,12,16,18,30)$. In all of these previous migrations, the new migrants were more aggressive and more fit than the resident population $(25,26,31)$. The recovery of both $\mathrm{A} 1$ and $\mathrm{A} 2$ mating types from a few fields, and in one case from the same plant, may indicate that the population of $P$. infestans within western Washington someday may become more similar to potato production regions in the Netherlands and Poland where sexually reproducing populations exist.

U.S. potato producers successfully manage late blight epidemics resulting from newly introduced genotypes of $P$. infestans provided they follow a protective fungicide spray program $(21,22)$. In addition, potato producers in Mexico have been successful in managing late blight with preventive foliar fungicide spray programs in areas where sexually reproducing $P$. infestans populations predominate $(21$; H. LozoyaSaldaña, personal communication). New studies indicate that fungicides for potato seed treatments can selectively impact the sporulation of $P$. infestans on tubers (24). If soilborne inoculum resulting from the formation of oospores becomes part of the etiology, the use of broad-spectrum fungicides applied to seed tubers and foliage will undoubtedly increase.

The genetic variation observed within populations of $P$. infestans in western Washington, the first area of the United States where metalaxyl insensitivity was detected and the first area in North America outside Mexico in which complex virulence pathotypes were identified, is probably the result of three separate migration events. It has become apparent that tomatoes and potatoes produced in home gardens, weed hosts such as hairy nightshade, and volunteer potatoes may become very important in the epidemiology and maintenance of some $P$. infestans genotypes in western Washington. Specifically, the US-11 genotype (A1) which was found on these hosts, in contrast to the US-8 genotype (A2) which was only found associated with potatoes, may retain a possible fitness advantage and help maintain a clonal population structure. Future studies that characterize this western Washington population need to include late blight lesions from both home gardens and weed hosts.

\section{ACKNOWLEDGMENTS}

This work was supported, in part, by the National Potato Council and USDA, ARS Potato Research Program. Plant Pathology New Series No. 0275, project 5123, College of Agriculture and Home Economics Research Center, Washington State University, Pullman. We thank Albert B. Bassi, Jr., Dean Glawe, Dennis Johnson, and Jack Rogers for critically reviewing this manuscript. B. Schuck provided invaluable technical assistance with the DNA fingerprint procedures.

\section{LITERATURE CITED}

1. Andrivon, D., and de Vallavieille-Pope, C. 1995. Race diversity and complexity in selected populations of fungal biotrophic pathogens of cereals. Phytopathology 85:897905.

2. Chycoski, C. I., and Punja, Z. K. 1996. Characteristics of populations of Phytophthora infestans from potato in British Columbia and other regions of Canada during 1993 to 1995. Plant Dis. 80:579-589.

3. Colon, L. T., and Budding, D. J. 1988. Resis-

Table 2. Pathogenicity phenotypes of 60 isolates of Phytophthora infestans collected in western Washington during 1996 and 1997

\begin{tabular}{|c|c|c|c|c|c|c|c|}
\hline \multicolumn{4}{|c|}{1996} & \multicolumn{4}{|c|}{1997} \\
\hline Host & No. of isolates & Race $^{a}$ & Octal $^{\text {b }}$ & Host & No. of isolates & Race & Octal \\
\hline US-11 Genotype ${ }^{c}$ & & & & US-11 Genotype ${ }^{c}$ & & & \\
\hline Potato & 1 & 7 & $0,0,4, \underline{0}$ & Potato & 1 & $2,5,7$ & $2,2,4, \underline{0}$ \\
\hline Tomato & 1 & $1,5,7$ & $4,2,4,0$ & Potato & 1 & $2,4,5,6,7$ & $2,7,4,0$ \\
\hline Potato & 1 & $1,4,7$ & $4, \underline{4}, 4, \underline{0}$ & Tomato & 2 & 1,7 & $4,0,4, \underline{0}$ \\
\hline Potato & 6 & $1,2,5,7$ & $6,2,4,0$ & Tomato & 1 & $1,5,8$ & $4,2,1,0$ \\
\hline Potato & 1 & $1,2,5,7,8$ & $6,2,6, \underline{0}$ & Tomato & 2 & $1,5,7$ & $4,2,4, \underline{0}$ \\
\hline Potato & 1 & $1,2,5,6,7$ & $6,3,4,0$ & Potato & 1 & $1,4,5,7$ & $4,6,4,0$ \\
\hline Tomato & 1 & $1,2,5,6,7,8$ & $6,3, \overline{6}, \underline{0}$ & Tomato & 1 & $1,3,5,7$ & $5,2,4, \underline{0}$ \\
\hline Potato & 3 & $1,2,4,5,7$ & $6,6,4, \underline{0}$ & Tomato & 1 & $1,2,7,8$ & $6,0,6, \underline{0}$ \\
\hline Potato & 4 & $1,2,4,5,7$ & $6, \underline{6}, 4, \underline{0}$ & Potato & 1 & $1,2,5,7,8$ & $6,2,6, \underline{0}$ \\
\hline Tomato & 3 & $1,2,4,5,7$ & $6, \overline{6}, 4, \underline{0}$ & Tomato & 1 & $1,2,4,5,7$ & $6,6,4, \underline{0}$ \\
\hline Potato & 2 & $1,2,4,5,7,8$ & $6,6,6,0$ & Potato & 3 & $1,2,4,5,6,7,8$ & $6,7,6,0$ \\
\hline Hairy nightshade $^{\mathrm{d}}$ & 1 & $1,2,4,5,6,7$ & $6,7, \underline{4}, \underline{0}$ & Potato & 1 & $1,2,3,5,7$ & $7,2,4, \underline{0}$ \\
\hline Potato & 1 & $1,2,3,5,7$ & $7,2,4,0$ & Potato & 1 & $1,2,3,4,5,7,8$ & $7,6,6,0$ \\
\hline Potato & 2 & $1,2,3,4,5,7$ & $7, \overline{6}, 4, \underline{0}$ & Tomato & 2 & $1,2,3,4,5,7$ & $7,6,4, \underline{0}$ \\
\hline Tomato & 1 & $1,2,3,4,5,7$ & $7,6, \underline{4}, \underline{0}$ & Potato & 3 & $1,2,3,4,5,7$ & $7,6,4, \underline{0}$ \\
\hline \multirow[t]{8}{*}{ Hairy nightshade } & 1 & $1,2,3,4,5,7,10$ & $7,6, \underline{4}, \underline{1}$ & & & & \\
\hline & & & & US-8 Genotype ${ }^{c}$ & & & \\
\hline & & & & Potato & 2 & $1,2,3,4,5,6,7,10$ & $7,7,4, \underline{4}$ \\
\hline & & & & Potato & 3 & $1,2,3,4,5,6,7,8,9,10$ & $7,7,7, \overline{4}$ \\
\hline & & & & Potato & 1 & $1,2,3,4,5,6,8,10$ & $7,7,2, \underline{4}$ \\
\hline & & & & US-14 Genotype ${ }^{\mathrm{c}}$ & & & \\
\hline & & & & Potato & 1 & $2,3,4,6,7,10$ & $3,6,4,4$ \\
\hline & & & & Potato & 1 & $1,2,3,4,5,6,7,10$ & $7,7,4, \underline{4}$ \\
\hline
\end{tabular}

\footnotetext{
${ }^{a}$ Summary of two or sometimes three detached potato leaflet assays using inverted water agar dishes as described by Tooley et al. (37).

${ }^{\mathrm{b}}$ R5, R6, and R8 potato differentials were not available for each detached leaflet test; R11 was not tested; the corresponding octal digits were underlined to reflect the missing data.

c US genotype designations sensu Goodwin et al. $(16,18)$.

d Solanum sarachoides.
} 
tance to late blight (Phytophthora infestans) in ten wild Solanum species. Euphytica S:7786.

4. Deahl, K. L., DeMuth, S. P., Sinden, S. L., and Rivera-Peña, A. 1995. Identification of mating types and metalaxyl resistance in North American populations of Phytophthora infestans. Am. Potato J. 72:35-49.

5. Deahl, K. L., Goth, R. W., Young, R., Sinden, S. L., and Gallegly, M. E. 1991. Occurrence of the A2 mating type of Phytophthora infestans in potato fields in the United States and Canada. Am. Potato J. 68:717-725.

6. Deahl, K. L., and Inglis, D. A. 1995. Occurrence of metalaxyl-insensitive Phytophthora infestans on Solanum sarachoides in northwestern Washington. Plant Dis. 79:540.

7. Deahl, K. L., Inglis, D. A., and DeMuth, S. P. 1993. Testing for resistance to metalaxyl in Phytophthora infestans isolates from northwestern Washington. Am. Potato J. 70:779795.

8. Drenth, A., Tas, I. C. Q., and Govers, F. 1994. DNA fingerprinting uncovers a new sexually reproducing population of Phytophthora infestans in the Netherlands. Eur. J. Plant Pathol. 100:97-107.

9. Easton, G. D., and Nagle, M. E. 1985. Timing and root absorption affecting efficiency of metalaxyl in controlling Phytophthora infestans on potato in northwestern Washington State. Plant Dis. 69:499-500.

10. Fry, W. E., and Goodwin, S. B. 1997. Reemergence of potato and tomato late blight in the United States. Plant Dis. 81:1349-1357.

11. Fry, W. E., Goodwin, S. B., Dyer, A. T., Matuszak, J. M., Drenth, A., Tooley, P. W., Sujkowski, L. S., Koh, Y. J., Cohen, B. A., Spielman, L. J., Deahl, K. L., Inglis, D. A., and Sandlan, K. P. 1993. Historical and recent migrations of Phytophthora infestans: Chronology, pathways, and implications. Plant Dis. 77:653-661.

12. Goodwin, S. B., Cohen, B. A., Deahl, K. L., and Fry, W. E. 1994. Migration from northern Mexico as the probable cause of recent genetic changes in populations of Phytophthora infestans in the United States and Canada. Phytopathology 84:553-558.

13. Goodwin, S. B., Cohen, B. A., and Fry, W. E. 1994. Panglobal distribution of a single clonal lineage of the Irish potato famine fungus. Proc. Natl. Acad. Sci. USA 91:11591-11595.

14. Goodwin, S. B., Drenth, A., and Fry, W. E. 1992. Cloning and genetic analyses of two highly polymorphic, moderately repetitive nuclear DNAs from Phytophthora infestans. Curr. Genet. 22:107-115.

15. Goodwin, S. B., Schneider, R. E., and Fry, W. E. 1995. Use of cellulose-acetate electrophoresis for rapid identification of allozyme genotypes of Phytophthora infestans. Plant Dis. 79:1181-1185.
16. Goodwin, S. B., Smart, C. D., Sandrock, R. W., Deahl, K. L., Punja, Z. K., and Fry, W. E. 1998. Genetic change within populations of Phytophthora infestans in the United States and Canada during 1994 to 1996: Role of migration and recombination. Phytopathology 88:939-949.

17. Goodwin, S. B., Spielman, L. J., Matuszak, J. M., Bergeron, S. N., and Fry, W. E. 1992. Clonal diversity and genetic differentiation of Phytophthora infestans populations in northern and central Mexico. Phytopathology 82:955-961.

18. Goodwin, S. B., Sujkowski, L. S., Dyer, A. T., Fry, B. A., and Fry, W. E. 1995. Direct detection of gene flow and probable sexual reproduction of Phytophthora infestans in northern North America. Phytopathology 85:473-479.

19. Goodwin, S. B., Sujkowski, L. S., and Fry, W. E. 1995. Rapid evolution of pathogenicity within clonal lineages of the potato late blight disease fungus. Phytopathology 85:669-676.

20. Goodwin, S. B., Sujkowski, L. S., and Fry, W. E. 1996. Widespread distribution and probable origin of resistance to metalaxyl in clonal genotypes of Phytophthora infestans in the United States and western Canada. Phytopathology 86:793-800.

21. Inglis, D. A., Gundersen, B. L., Ludy, R. L., and Powelson, M. L. 1998. Results of the 1997 North American late blight fungicide trial. (Abstr.) Am. J. Potato Res. 75:279.

22. Inglis, D. A., Gundersen, B. L., Powelson, M. L., and Cappaert, M. R. 1997. Evaluation of foliar fungicide spray programs across North America for control of late blight of potato. (Abstr.) Am. Potato J. 74:436-437.

23. Inglis, D. A., Johnson, D. A., Legard, D. E., Fry, W. E., and Hamm, P. B. 1996. Relative resistances of potato clones in response to new and old populations of Phytophthora infestans. Plant Dis. 80:575-578.

24. Inglis, D. A., Powelson, M. L., and Dorrance, A. E. Effect of registered potato seed piece fungicides on tuberborne Phytophthora infestans. Plant Dis. In press.

25. Kato, M., Mizubuti, E. S., Goodwin, S. B., and Fry, W. E. 1997. Sensitivity to protectant fungicides and pathogenic fitness of clonal lineages of Phytophthora infestans in the United States. Phytopathology 87:973-978

26. Lambert, D. H., and Currier, A. I. 1997. Differences in tuber rot development for North American clones of Phytophthora infestans. Am. Potato J. 74:39-43.

27. Legard, D. E., Lee, T. Y., and Fry, W. E. 1995. Pathogenic specialization in Phytophthora infestans: Aggressiveness on tomato. Phytopathology 85:1356-1361

28. Maniatis, T. A., Fritsch, J. F., and Sambrook, J. 1982. Molecular Cloning: A Laboratory Manual. Cold Springs Harbor Laboratory, Cold Spring Harbor, NY.
29. Matuszak, J. M., Fernandez-Elquezabal, J Gu, W. K., Villarreal-Gonzalez, M., and Fry, W. E. 1994. Sensitivity of Phytophthora infestans populations to metalaxyl in Mexico: Distribution and dynamics. Plant Dis. 78:911916.

30. Miller, J. S., Hamm, P. B., and Johnson, D. A. 1997. Characterization of the Phytophthora infestans population in the Columbia Basin of Oregon and Washington from 1992 to 1995. Phytopathology 87:656-660.

31. Miller, J. S., Johnson, D. A., and Hamm, P. B. 1998. Aggressiveness of isolates of Phy tophthora infestans from the Columbia Basin of Washington and Oregon. Phytopathology 88:190-197.

32. Peters, R. D., Platt, H. W., Hall, R., Driscoll, A., MacPhail, A., Jenkins, S., Connors, E., Medina, M., and MacLean, V. 1997. Continuing characterization studies of evolving populations of Phytophthora infestans causing late blight of potato in Canada. (Abstr.) Am. Potato J. 74:456.

33. Peters, R. D., Platt, H. W., Hall, R., Maxwell, P. W., Medina, M., Connors, E., and Powell, S. 1996. Monitoring evolving populations of Phytophthora infestans causing late blight of potato in Canada. (Abstr.) Am. Potato J. 73:376.

34. Pittis, J. E., and Shattock, R. C. 1994. Viability, germination and infection potential of oospores of Phytophthora infestans. Plant $\mathrm{Pa}-$ thol. 43:387-396.

35. Sujkowski, L. S., Goodwin, S. B., Dyer, A. T. and Fry, W. E. 1994. Increased genotypic diversity via migration and possible occurrence of sexual reproduction of Phytophthora infestans in Poland. Phytopathology 84:201207.

36. Sukjowski, L. S., Goodwin, S. B., and Fry, W. E. 1996. Changes in specific virulence in Polish populations of Phytophthora infestans 1985-1991. Eur. J. Plant Pathol. 102:555-561.

37. Tooley, P. W., Fry, W. E., and Villarreal-Gonzalez, M. J. 1985. Isozyme characterization of sexual and asexual Phytophthora infestans populations. J. Hered. 76:431-435.

38. Tooley, P. W., Sweigard, J. A., and Fry, W. E. 1986. Fitness and virulence of Phytophthora infestans isolates from sexual and asexual populations. Phytopathology 76:1209-1212.

39. Tuite, J. 1969. Plant Pathological Methods. Burgess Publishing Co., Minneapolis, MN

40. Vanderplank, J. E. 1968. Disease Resistance in Plants. Academic Press, New York.

41. Washington Agricultural Statistics Service. 1991. Washington Agricultural Statistics 1990-1991. Wash. Agric. Stat. Serv. Olympia, WA.

42. Washington Agricultural Statistics Service. 1997. Washington Agricultural Statistics 1996-1997. Wash. Agric. Stat. Serv. Olympia, WA. 